\title{
A New Public Health Paradigm for Alzheimer's Disease Research
}

\author{
Mario D Garrett* and Ramon Valle \\ San Diego State University, California, USA
}

Received: July 21, 2015; Accepted: November 18, 2015; Published: December 19, 2015

*Corresponding author: Mario D. Garrett, Professor, School of Social Work, San Diego State University, San Diego, California, USA, 92182-4119, Tel: (619) 594-2818; Fax: (619) 594-5991; E-mail: mgarrett@mail.sdsu.edu

\begin{abstract}
In industrialized countries Alzheimer's disease is becoming a pandemic. Over the next few decades one in six people are predicted to have Alzheimer's disease. This will evolve into a public health tragedy. Unfortunately there is a problem with dementia research. After more than a century of research we cannot answer basic questions about the disease, whether the biomarkers are truly the disease or whether these biomarkers are symptoms of another yet unknown disease. This paper summarizes the literature to show that there are other correlates-and possible causes-of Alzheimer's disease that have not received attention, but if the disease is approached from a public health perspective, then the disease can be organized under the four potential integrated processes of Trauma, Penumbra, Perfusion and Plasticity. Through this re-framing of the disease as a public health problem an opportunity emerges that can expand and reinvigorate research in Alzheimer's disease. Such new insights can elucidate a better and fuller understanding of the disease and provide some real hope to defining a road map to a cure.
\end{abstract}

Keywords: Alzheimer's disease; public health; trauma, penumbra, perfusion; plasticity

\section{Introduction}

Alzheimer's disease is evolving as a disease of global proportions. With life expectancy in industrialized countries inching up to 85 years, and where one-third of those of this age are predicted to have Alzheimer's disease [1], it is anticipated that one in six of the total population of industrialized countries will have the disease. Alzheimer's disease is maturing into a 21st century pandemic. But there is a problem. In the last hundred years of research we have gained very little significant insight into stopping this disease.

The search for exclusive biomarkers for Alzheimer's disease-a neuropathology that signifies the deterioration of behavior associated with Alzheimer's disease-continues to elude researchers. Alzheimer's paradigm is still too narrowly defined through biomarkers-biological, genetic and chemicalwhen in the literature there are other factors that are shown to contribute to this disease. The aim of this paper therefore is to highlight alternate interpretations of Alzheimer's disease mechanisms and to readdress why such mechanisms have been left out of the National Institute on Aging-Alzheimer's Association (NIA-AA) 2011 research agenda for Alzheimer's disease [2].

The Amyloid Cascade hypothesis is the dominant theory in Alzheimer's disease [3]. This theory postulates that the deposition of the amyloid- $\beta$ peptide (plaques) in the brain is a central event in Alzheimer's disease pathology, followed by tau protein deposits (tangles) that clog up the brain causing impaired cognition leading to dementia. As a result of this theory, research on Alzheimer's disease has exclusively focused on neurobiology and biochemistry. This exclusivity was reinforced when the Amyloid Cascade hypothesis was adopted by the 2011 NIA-AA guidelines that concentrate on identifying biomarkers in the preclinical stage of the disease [4].

But research continues to expose anomalies that cannot be easily explained by these guidelines [5,6]. Additionally, there is now a valid and persuasive criticism of the current research methodologies in Alzheimer's disease: the lack of evidence that biomarkers cause the disease; that the disease behaves more as a syndrome with diffuse expression; and that the methodology used to study the clinical aspects of Alzheimer's disease is unreliable and invalid [7-9]. In particular, although the plaques and tangles seem to be more prevalent among people with Alzheimer's disease there are people that live independently and unaware of this neuropathology in their brain $[10,11]$. While in human clinical trials, patients using experimental drugs that succeeded in removing or inhibiting the development of plaques, showed worse cognitive performance than the controls [12-14].

The problem was then-and is now-that the relationship between the neurobiology and the disease is not distinct. Despite such lack of evidence, the Amyloid Cascade hypothesis remains resilient due to the lack of counter paradigms to challenge its dominance in guiding Alzheimer's disease research [15]. Emerging clinical studies are however taking a more pragmatic approach; showing how lifestyle changes reverses cognitive decline and how other factors are involved in Alzheimer's disease $[16,17]$. As a result, there is growing support for a broader approach public health perspective to studying the causes and mechanisms of Alzheimer's disease. Under this perspective the seeming disparate processes of Alzheimer's disease can be 
organized under four related processes of Trauma, Penumbra, Plasticity and Perfusion.

Diagram: Schematic representation showing an initial Trauma causing a Penumbra that is moderated and mediated by Plasticity and Perfusion.

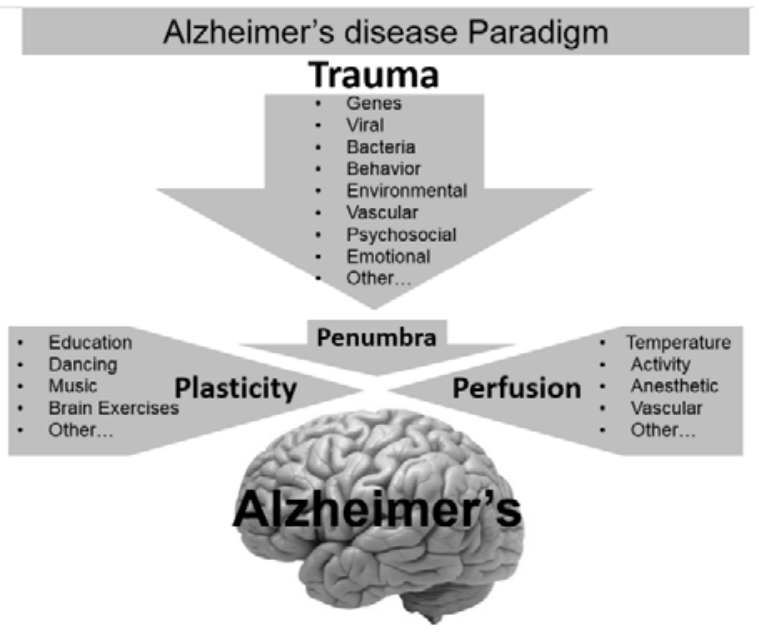

The Diagram provides a schematic diagram of a model that defines how these four processes might interact in order to permit research to understand and examine delaying or preventing Alzheimer's disease. In this model an initial Trauma that turns into a Penumbra-an initial cluster of cell deathwhich is more likely to grow and cause Alzheimer's disease if the brain is denied two mediating and moderating factors: the lack of adequate cerebral Perfusion and reduced Plasticity to assimilate the Penumbra. Without these moderating factors of Plasticity and Perfusion, the Penumbra will grow and affect larger areas of the brain. This broader interpretation of Alzheimer's disease assimilates both the traditional Amyloid Cascade hypothesis, but also broadens the scope to address contributing factors that are emerging in public health.

\section{Trauma}

The initial trauma that starts Alzheimer's disease is unknown. Although most of the research focuses on genetic mechanisms, there is growing evidence that other, more relevant, mechanisms exist: viral (HIV/AIDS, herpes simplex virus type I, Varicella zoster virus, cytomegalovirus, Epstein-Barr virus), bacteria (syphilis and Lyme-disease/borrelia), parasites (toxoplasmosis, cryptococcosis and neurocysticercosis), behavior (Alcohol, cigarette smoking, recreational drugs, concussion/mild/severe brain trauma) environmental elements (possibly aluminum), infections (possibly prions such as in Cretchfeldt-Jakobs disease), vascular causes (stroke, multiple-infarct dementia hydrocephalus, and injury or brain tumors) and emotional trauma. There is literature that correlates all of these factors with Alzheimer's disease, but none of these factors appear in the NIAAA research agenda for Alzheimer's disease.

\section{Genes}

Although there is a growing list of genes that could determine dementia, most cases of Alzheimer's disease are sporadic and have unknown causes [18]. The Genetic Testing Registry identifies eleven specific genes that are being studied [19], but other neurobiological diseases also have the same genetic markers, such as: Parkinson's disease, Lewy bodies, CretchfeldtJakobs disease, Huntingdon's disease, Wilson's disease, Progressive supranuclear Palsy, hydrocephalus, Conti cobesiler degeneration, multiple scelorisis, Down's syndrome, meta chronic leucodystropy and space occupying lesions [19]. In terms of genetic markers, there is no pure type of Alzheimer's disease. It could be that the disease exists in a continuum, although 'mixed' dementias are rarely diagnosed as the majority of diagnostic procedures are psychologically biased toward a diagnosis of Alzheimer's disease [20].

\section{Viral}

As with genetic research, virus infections that specifically and exclusively cause Alzheimer's disease have not been identified. But there is growing evidence that viruses are important in Alzheimer's disease and other neurological disorders [21]. The primary virus that we know causes dementia is HIV/AIDS. The cumulative risk of developing HIV-Dementia during the lifetime of an HIV+ person was 5-20\% [22], which is increasing to 38$40 \%$ [23]. HIV-AIDS is also prone to an opportunistic infection cytomegalovirus that also affects the central nervous system and can cause dementia independently [24].

Herpes simplex virus type I-non-sexually transmittedremains ubiquitous [25]. Once infected, the virus remains in the peripheral nervous system and cause encephalitis that affects the same regions of the central nervous system (temporal and frontal cortex, and hippocampus) as those most affected by Alzheimer's disease [26]. Emerging studies [27] report that there is an increased risk of Alzheimer's disease when the virus is present in combination with the genetic marker of APOE- $\varepsilon 4$ allele, while independently neither increase the risk of Alzheimer's disease. Similar to the herpes simplex virus type I, the Varicella zoster virus has also been more prevalent among patients with atherosclerotic dementia [28]. In contrast, controlsschizophrenics or patients with other psychiatric disorders or in groups of healthy people-had lower prevalence. Similarly, chlamydia pneumonia infections are found in 90\% of Alzheimer's disease patients, with the virus itself found inside the plaques in their brain [29]. These studies are still correlational, but they point out a growing interest in viral infections and how they can cause or promote Alzheimer's disease.

\section{Bacteria}

Alois Alzheimer-who identified the disease in 1907-was primarily interested in syphilis. For centuries, other than just old age, syphilis was the main and only known cause of dementia before Alzheimer's disease was identified. Today, although neurosyphilis is rare-where the bacteria causes neuropathology that results in clinical features of dementia-another bacterium gaining interest is Lyme disease. Lyme dementia has become a greater concern because it is the most common vector-borne disease in the northern hemisphere [30]. Since there is no cure 
for Lyme disease, the expectation is that more patients will develop Lyme dementia in the near future [31].

\section{Behavior}

Alcohol has had a long history with mental health and is already a public health concern. There has been an increasing interest in the relationship between a history and heavy intake of alcohol with Alzheimer's disease. There is now evidence that this relationship is independent and not mediated by history of hypertension, cardiovascular disease, or head injury [32]. Meta-analyses studying the relationship between alcohol consumption and risk of Alzheimer dementia and dementia reported a 'J' shaped relationship, with moderate drinking showing moderate protection $[33,34]$. A history of high alcohol intake has been shown to increase the risk of Mild Cognitive Impairment and Alzheimer's disease in a large Canadian study [35], in a US study [36] and; in a Brazilian study [37]. Excessive alcohol use may damage the brain due to toxic effects of alcohol, metabolic changes in the brain, neurotransmitter imbalances and nutritional deficiency injury [38].

Concussion or mild traumatic brain injuries (MTBI) - incurred through falls, motor vehicle accidents, trauma from explosives, and sports-related activity-account for $75 \%$ of all traumatic brain injuries sustained in the United States [39]. MTBI are seen at all ages from youth [40] to adults [41,42]. Sustaining only one or two concussions has permanent neurological repercussions [43] and is known to be risk factors for developing Alzheimer's disease later in life [44-46]. Smoking and secondhand smoking is associated with a 50-60\% risk of Alzheimer's disease [47-51] having a dose effect-the more you smoke the higher the risk $[52,53]$. This is also related to the vascular changes.

\section{Vascular}

In a review of the literature [54], researchers reported that stroke is one of the leading causes of disability, Alzheimer's disease and death in the USA. While many stroke victims improve, others worsen. Three months after a stroke, $25-33 \%$ of patients express Alzheimer's disease, and an even greater proportion have severe cognitive impairment [55]. Stroke doubles the risk of Alzheimer's disease even after adjusting for age, sex, education, and exposure to individual stroke risk factors [56]. With over 790,000 victims of stroke each year in the United States, it is an important etiology of Alzheimer's disease that is often neglected in research.

\section{Environmental}

Epidemiological studies suggest that there is a link between metal, especially aluminum and Alzheimer's disease. Aluminum may not be as innocuous as once thought since it may actively promote the onset and progression of Alzheimer's disease [57], as a form of chronic aluminum neurotoxicity [58]. Although rare nowadays, it was first described among dialysis patients [59] where aluminum acted as a neurotoxin trauma that caused Alzheimer's disease [60].

Similar to plaques and tangles-misshapen amyloid and tau proteins that clamp together-a novel form of human prion disease is linked with bovine spongiform encephalopathy (BSE) and Creutzfeldt-Jakob's disease [61]. The hallmark of prion disease is the accumulation of misfolded protein that is toxic to neuronal cells [62].

\section{Emotional}

Adverse childhood experiences start a cascade of risk behaviors that are associated with enduring changes in the nervous, endocrine, and immune systems [63]. In a Californian study of 1116 elderly community residents, self-reported cognitive function was lower than expected for those who had experienced sustained economic hardship, even after adjusting for age, sex, and co-morbidity [64]. Poverty, larger family size and urban residence were associated with increased Alzheimer's disease risk [65]. Some adverse childhood events continue to have a negative effect on later-life cognitive performance on some people, while others seem immune, underlying the necessity to consider events individually and not as global test scores [66].

All these variables-genetic, viral, bacteria, behavior, environmental, vascular, and emotional-act as a trauma, a shock, to the brain, affecting the brain independently or in combination. There might be other traumas that are as yet unidentified. But once there is a trauma to the brain, then the body reacts in a very specific way. Researchers a century ago reported that there was a shadow, a halo that follows from a trauma. Clinically, this is referred to as a penumbra. There are indications [67] that although the origins of the trauma in Alzheimer's disease are undefined, the process suggests that cell death extends beyond the region of damaged tissue. Trauma results in an initial assault of cell death followed by a penumbra a broader cluster of neuronal death.

\section{Penumbra}

Perusini made an interesting early observation that: 'The glia, then, develop around the deposits and encapsulates them just as they usually do with every foreign body (in the broadest sense)' [68] (p121). Such an interpretation suggests that the growth of plaques could be a protective response, where the initial toxic trauma is enveloped into harmless mass by other cells [69]. Singular or multiple traumas-like a stroke-kill off a significant number of neurons and, in response the brain protects itself with an envelope of white cells (glial) transforming the toxic clump inert. To some degree, this happens all the time. The brain is in constant state of change. Alois Alzheimer himself identified this penumbra as a halo, or a shadow: 'Sometimes there are also rodlike cell elements of obvious glial origin lying in the halo' [70] (p80). The dual nature of this process-where the damage is quarantined and contained, while in other cases there is a further shockwave of neuronal death beyond the initial trauma-is an enigma. Two possible moderators of this spread of the penumbra is cerebral plasticity-potential for neurons and glial cells to grow; and perfusion-blood flow in the brain that provides the energy-hungry neurons the necessary nutrients, required to function and repair themselves. 


\section{Plasticity}

Within a public health approach, one of the moderating or mediating factors that affect the development of Alzheimer's disease is Plasticity. Although the brain naturally shrinks with age, brain atrophy in Alzheimer's disease is five-fold higher during 7-10 years of the disease, translating to approximately $200-400 \mathrm{~g}$ of brain mass loss [71]. Such loss is in addition to the plaques and tangles [72]. But there is a process that counteracts this loss. Ernesto Lugaro in the early 1906 was responsible for introducing the term plasticity into neuroscience [73]. Lugaro refers to 'psychic plasticity; plasticity of the neurons; plasticity of the neurofibrils' a process that continues throughout life in order to establish new connections between neurons [74]. Such development is apparent in maturation, learning and even functional learning after brain damage throughout the lifespan [75]. In some cases neuronal growth takes place on a daily basis [76]. A growing body of evidence is exposing the capacity of the brain to regenerate throughout lifespan through education $[77,78]$.

\section{Education}

In the now famous Nuns' Study [79] Snowdon found that $8 \%$ of the nuns who had the most severe level of neurological disease in their brain behaved and acted free from dementia. The researchers explained this finding by arguing that education is an important moderating factor [79]. There seems to be an inverse dose-response relation between education and Alzheimer's disease [80], with education acting as a proxy for cognitive reserve [81]. Education might not only increase capacity and plasticity but might also modify behavior away from risk behaviors that promote Alzheimer's disease [82].

\section{Dancing/Music/Body Movement}

The power of music and dancing-including other social activities-correlate with positive gains in cognitive tests. Institutionalized older adults improved faster than communitybased participants in studies that promoted music, dance, singing, food preparation, and selecting pictures [83]. The results may be more than just exercise and social engagement, although the exact mechanism is unknown [84]. In a now classic longitudinal study [85] looking at the frequency of participation in leisure activities and physical-activity, after a follow-up period of 5.1 years only reading, playing board games, playing musical instruments, and dancing were associated with a reduced risk of Alzheimer's disease and vascular dementia. Because these activities were studied in addition to physical activity, they provided an additional benefit to cerebral perfusion. Numerous studies have measured brain volumes of professional pianists, reporting that the more hours a musician played the more heavily myelinated or tightly packed their white matter axons were [86]. Such changes might also be specific to the type of learning, so that white matter architecture differs between musicians and nonmusicians [87].

\section{Brain Exercises}

The utility of cognitive training programs in delaying cognitive decline has gathered momentum since the first large randomized controlled double-blind trial using a commercially available cognitive training program $[88,89]$. The two most widely cited ongoing studies are ACTIVE and IMPACT [90,91]. Even patients with early to moderate Alzheimer's disease using computer exercises had better performance on cognitive tests [92]. Gains were recorded in standardized measures of memory and attention ten years after the intervention, on tests that were not part of the initial intervention [93]. Since there was growth in the hippocampus these benefits seem to involve brain plasticity [94]. The idea that interacting with the environment continues to regenerate and change the brain throughout life-both positively and negatively-supports the hypothesis that brain plasticity offers a possible mediating mechanism through which the brain might be provoked to repair itself [95]. Cognitive training programs, music and dancing have been associated with brain growth [94.96], and such plasticity/neurogenesis seems to delay the onset of Alzheimer's disease [97,98].

\section{Cerebral Perfusion}

The fourth process in this public health model is Perfusionblood flow to the brain. At autopsy, $60-90 \%$ of patients with Alzheimer's disease exhibit variable cerebrovascular pathology and almost 30\% show evidence of cerebral infarction [99,100]. As part of a multistage theory of Alzheimer's disease, having the necessary blood flow to the brain is a linchpin of a healthy brain. Evidence is mounting that vascular risk factors launch a cascade of cellular and molecular changes that initiate cognitive deficits and eventual progresses to Alzheimer's disease [101]. There is a strong indication that there is an association between diminished (hypo) perfusion and Alzheimer's disease. Cerebral perfusion is a balance that must be maintained within narrow margins. Too little pressure causes brain tissue to become ischemic-shortage of oxygen and glucose needed for cellular metabolism-while too much pressure causes cellular damage. Cerebral perfusion is closely aligned with vascular dementia. Although the brain is only $2 \%$ of the body weight it consumes $15-20 \%$ of all cardiac output and $20 \%$ of all oxygen in the body. Such balance is maintained by complex mechanisms, and one such mechanism-through vasoconstriction and vasodilation-is temperature [102].

\section{Temperature}

Perhaps not surprisingly, older adults have slightly lower body temperatures than younger adults [103]. Average temperature for older adults is $97.7^{\circ}$, lower than the $98.6^{\circ}$ $\mathrm{F}$ benchmark. Although a systematic review reports great variance in temperature across gender and individuals, making aggregate statistics unreliable predictors [104]. Biologically, a lower temperature seems to enhance longevity. In the Baltimore Longitudinal Study of Aging, men with a core body temperature below the median lived significantly longer than men with body temperature above the median [105]. However the contradiction is that lower temperature might also results in lower perfusion. The association of age with Alzheimer's disease might be mediated by decrease in body temperature, an avenue of research that remains untapped. 


\section{Activity}

Perfusion can also be controlled by activity. Being active enhances the blood flow to the brain. In a four-year longitudinal study [106] retirees who elected to become physically inactive exhibited significant decline in perfusion while those who continued to work or engage in regular activities maintained more constant perfusion levels. Interestingly, the relationship between perfusion and cognition was acknowledged when the researchers reported that active retirees scored better on cognitive testing after a four-year follow-up. Blood flow to the body is important for all organs, including the brain. Being physically active has been shown to decrease the incidence or delays the onset of Alzheimer's disease [107,108],[94]. So much so that Alzheimer's disease can be defined as a 'diseasome of physical inactivity' [109], where activity delays such risks [110].

\section{General Anesthetic}

Themostcommon sudden hypo perfusionoccursundergeneral anesthetic [111]. Evidence for anesthesia-induced neurotoxicity is mounting suggesting that general anesthetics may be neurotoxic to both young and aging brains [112]. In a population of healthy elderly patients, undergoing non-vascular abdominal surgery [113] cerebral desaturation-an indication of hypoperfusionoccurs in one in four patients. When this happens, those patients have higher incidence of early postoperative cognitive decline and longer hospital stay. Maintaining a consistently healthy cerebral perfusion is important to brain health. It would be informative to see changes in the penumbra of stroke patients who undergo general anesthetic, an avenue of research that still needs to be undertaken. There are many similarities between vascular dementia and Alzheimer's disease. Something that even Alzheimer entertained: 'The question is: are these cases to be assigned to Dementia senilis or to arteriosclerosis? ...Perhaps this arrangement of atrophy could be related to the vascular supply of the temporal lobe.' [70] (p97). Since vascular dementia is the second largest category of dementia it is important to address the relationship and difference. Alzheimer's disease and vascular dementia are the two most common forms of dementia, sharing many common medications, pathological, symptomatic and neurochemical features [20].

\section{Discussion}

The public health model described and presented in this introduction defines how four processes might interact to generate or possibly retard or delay Alzheimer's disease. An initial Trauma that turns into a Penumbra is more likely to cause Alzheimer's disease if the brain is denied two mediating and moderating factors: a lack of adequate cerebral Perfusion, or if there is a lack of Plasticity. Without these two factors the penumbra will grow and affect larger areas of the brain-and such damage will go beyond plaques and tangles. This broader public health interpretation of Alzheimer's disease assimilates both the traditional Amyloid Cascade hypothesis [3] and broadens the scope to include emerging research in the public health arena, some of which were introduced in this paper. More importantly, these mechanisms also address the mounting anomalies in Alzheimer's disease research. There is more than one trauma that results in similar outcomes. The initial trauma might result in a penumbra which might or might not progress. The neurological disease might or might not affect cognition. These multiple pathological mechanisms-that all inter-relatehave not been explored comprehensively. A healthy lifestyleand the effect this has on cerebral perfusion-has been shown to delay Alzheimer's disease. There is also a century of work that looks at how learning and education seems to have a protective influence against Alzheimer's disease-plasticity, neurogenesis and capacity can delay, protect, and recover-even after a major trauma like a stroke [114]. Older age does not necessarily lead to Alzheimer' disease. When Henrikje van Andel-Schipper died in 2005 , she was the oldest woman at age 115 , and in post-mortem examination her brain showed no signs of neuropathology [115]. It seems some people escape dementias. Long-lived older adults escape or delay dementias because they maintain adequate perfusion, have functional plasticity and have evaded major traumas [116].

Without a broader a public health approach dementia research will remain confined within research silos away from any chance of rich crosspollination. But within this public health a more nuanced approach to the many different types of dementias can be explored. Different causes of the many types of dementias might hold unique insights into their unique cures [17]. Of equal importance is to examine how most older adults escape Alzheimer's disease, an approach that can be promoted within a public health, rather than within a disease-model.

\section{Conclusion}

By accepting the evidence of possible external traumas (viral, bacterial, biological, chemical, environment, behavioral) that can initiate Alzheimer's disease, and then assigning importance to the role of perfusion and plasticity to delay the growth of the penumbra, this approach reframes the disease as a public health issue with potential public health solutions. Such a methodology will include educational as well as legislative programs that reduce and lower the exposure to traumas. Reduction of concussions (in sport, military, recreational activities) should be made a priority. Programs that educate on the effects of smoking and heavy drinking on the brain will need to be promoted, as well as programs that address environmental toxicity both in the air and in our water. For perfusion, increasing activity provides an incentive for families to promote daily activity among adults of all ages. City walkability programs, and social engagement programs all promote walking, swimming, light exercise, gardening among other activities. The family's role remains central in improving plasticity since engaging patients in social activities, dancing, music and other cognitive exercise will have both protective factors as well as showing promise of reversing the attrition from the disease. Such pragmatic approaches have already been shown to be efficacious [16]. Adjusting the focus to include environmental and social components brings the disease squarely into the public health arena where a broader array of scientists, academics and clinicians can break down research silos and actively work together to address the emerging pandemic of Alzheimer's disease. 


\section{References}

1. Hebert LE, Weuve J, Scherr PA, Evans DA. Alzheimer disease in the United States (2010-2050) estimated using the 2010 Census. Neurology. 2013;80(19):1778-1783. doi: 10.1212/ WNL.0b013e31828726f5.

2. Jack CR, Albert MS, Knopman DS, McKhann GM, Sperling RA, Carrillo $\mathrm{MC}$, Thies $\mathrm{B}$, Phelps $\mathrm{CH}$. Introduction to the recommendations from the National Institute on Aging-Alzheimer's Association workgroups on diagnostic guidelines for Alzheimer's disease. Alzheimer's \& Dementia. 2011;7(3):257-62. doi: 10.1016/j.jalz.2011.03.004.

3. Hardy JA, Higgins GA. Alzheimer's disease: the amyloid cascade hypothesis. Science. 1992;256(5054):184-185.

4. Jack CR,Jr Knopman DS, Jagust WJ, Shaw LM, Aisen PS, Weiner MW,et al. Hypothetical model of dynamic biomarkers of the Alzheimer's pathological cascade. Lancet Neurology. 2010;9(1):119-128.DOI: /101016/S1474-4422(09)70299-6.

5. Holtzman DM, Morris JC, Goate AM. Alzheimer's disease: the challenge of the second century. Science Translational Medicine. 2011;3(77):77sr1.doi: 10.1126/scitranslmed.3002369.

6. Golde TE,Schneider LS,Koo EH. Anti-A $\beta$ therapeutics in Alzheimer's disease: the need for a paradigm shift. Neuron. 2011;69:203-213.

7. Whitehouse PJ,George D. The Myth of Alzheimer's Disease. New York. 2007;St Martin's Press.

8. Lock M. The Alzheimer Conundrum: Entanglements of Dementia and Aging. Princeton University Press, 2013

9. Garrett MD, Valle RJ. A Methodological Critique of The National Institute of Aging and Alzheimer's Association Guidelines for Alzheimer's disease, Dementia and Mild Cognitive Impairment. Dementia. 2014; DOI: 101177/1471301214525166 DOI /101177/1471301214525166.

10. Tomlinson BE, Blessed G, Roth M. Observations on the brains of demented old people. Journal of the Neurological Sciences. 1970;11(3):205-242. DOI: /101016/0022-510X(70)90063-8.

11. Dickson DW, Crystal HA, Mattiace LA, Masur DM, Blau AD, Davies P, et al. Identification of normal and pathological aging in prospectively studied nondemented elderly humans. Neurobiology of Aging 1992;13(1):179-189. DOI: /101016/0197-4580(92)90027-U.

12. Gilman S, Koller M, Black RS, Jenkins L, Griffith SG, Fox NC, et al Clinical effects of Abeta immunization (AN1792) in patients with AD in an interrupted trial. Neurology. 2005;64(9):1553-1562.DOI: /101212/01WNL0000159740169843C.

13. Boche D, Donald J, Love S, Harris S, Neal JW, Holmes C et al. Reduction of aggregated tau in neuronal processes but not in the cell bodies after Abeta42 immunisation in Alzheimer's disease. Acta Neuropathologica. 2010; 120(1):13-20. DOI: /101007/s00401-010-0705-y.

14. Rinne JO, Brooks DJ, Rossor MN, Fox NC, Bullock R, Klunk W, et al. C-PiB PET assessment of change in fibrillar amyloid- $\beta$ load in patients with Alzheimer's disease treated with bapineuzumab: a phase 2, double-blind, placebo-controlled, ascending-dose study. The Lancet Neurology. 2010;9(4):363-372. DOI: /101016/S14744422(10)70043-0.

15. Karran E, Mercken M, De Strooper B. The amyloid cascade hypothesis for Alzheimer's disease: an appraisal for the development of therapeutics. Nature Reviews Drug Discovery. 2011;10(9):698-712. doi:10.1038/nrd3505.

16. Bredesen DE. Reversal of cognitive decline: a novel therapeutic program. Aging (Albany NY). 2014 Sep;6(9):707

17. Baumgart M, Snyder HM, Carrillo MC, Fazio S, Kim H, \& Johns H. Summary of the evidence on modifiable risk factors for cognitive decline and dementia: A population-based perspective. Alzheimer's \& Dementia. 2015;11(6):718-726. doi: 10.1016/j.jalz.2015.05.016.

18. Bird T. GeneReview. Accessed. 2014; http://wwwncbinlmnihgov/ books/NBK1161/

19.GTR-Genetic Testing Registry. Accesses. 2104;http:// wwwncbinlmnihgov/gtr/conditions/C0002395/

20. Kalaria R. Similarities between Alzheimer's disease and vascular dementia. Journal of the Neurological Sciences. 2002;203-204:29-34. DOI: /101016/S0022-510X(02)00256-3.

21. Karim S,Mirza Z,Kamal M,Abuzenadah A,Azhar E,Al-Qahtan M,et al.The Role of Viruses in Neurodegenerative and Neurobehavioral Diseases. CNS and Neurological Disorders-Drug Targets. 2014;13(7):12131223.

22. McArthur JC,Hoover DR,Bacellar H,Miller EN,Cohen BA,Becker JT, et al. Dementia in AIDS patients: incidence and risk factors. Neurology. 1993;43(11):2245-2252.DOI: /101212/WNL43112245.

23. McArthur JC. HIV dementia: an evolving disease. Journal of Neuroimmunology. 2004;157(1-2):3-10.DOI: /101016/ jjneuroim20040804.

24. Neuenburg JK,Brodt HR,Herndier BG,Bickel M,Bacchetti P,Price RW,et al. HIV-related neuropathology, 1985 to 1999: rising prevalence of HIV encephalopathy in the era of highly active antiretroviral therapy. Journal of Acquired Immune Deficiency Syndromes. 2002;31(2):171177.

25.Xu F,Sternberg MR,Kottiri BJ,McQuillan GM,Lee FK,Nahmias AJ, et al. Trends in herpes simplex virus type 1 and type 2 seroprevalence in the United States. Jama. 2006; 296(8): 964-973.

26. Ball M. Limbic predilection in Alzheimer's dementia: is reactivated herpes virus involved?. Canadian Journal of Neurological Science. 1982;9(3):303-306.

27. Itzhaki RF,Lin WR,Shang D,Wilcock GK,Faragher B,Jamieson GA. Herpes simplex virus type 1 in brain and risk of Alzheimer's disease. The Lancet.1997;349(9047):241-244.DOI: /101016/S01406736(96)10149-5.

28. Lycke E,Norrby R,Roos BE. A serological study on mentally ill patients with particular reference to the prevalence of herpes virus infections. The British Journal of Psychiatry. 1974;124,273-279.DOI: /101192/ bjp1243273.

29. Borrelia burgdorferi Honjo K, van Reekum R, Verhoeff NP. Alzheimer's disease and infection: do infectious agents contribute to progression of Alzheimer's disease?. Alzheimer's Dementia. 2009;5(4): 348-360. doi: 10.1016/j.jalz.2008.12.001.

30. Pearson S. Recognising and understanding Lyme disease. Nursing Standard. 2014;29(1):37-43. DOI: /107748/ns29137e9073.

31. Blanc F,Philippi N,Cretin B,Kleitz C,Berly L,Jung B,de Seze J. Lyme Neuroborreliosis and Dementia. Journal of Alzheimer's Disease. 2014;41(4):1087-1093.

32. Kuźma E, Llewellyn DJ, Langa KM, Wallace RB, Lang IA. History of alcohol use disorders and risk of severe cognitive impairment: A nineteen-year prospective cohort study. The American Journal of Geriatric Psychiatry. 2014;22(10):1047-1054.DOI: /101016/ jjagp201406001.

33. Anstey KJ, Mack HA, \& Cherbuin N. Alcohol consumption as a risk 
factor for dementia and cognitive decline: meta-analysis of prospective studies. American Journal of Geriatric Psychiatry. 2009;17(7):542555. DOI: /101097/JGP0b013e3181a2fd07.

34. Peters R, Peters J, Warner J, et al. Alcohol dementia and cognitive decline in the elderly: a systematic review. Age Ageing. 2008;37(5):505-512. DOI: /101093/ageing/afn095.

35. Thomas VS, Rockwood KJ. Alcohol abuse, cognitive impairment, and mortality among older people. Journal of the American Geriatric Society. 2001;49(4):415-420. DOI: /101046/j15325415200149085x.

36. Perreira KM, Sloan FA. Excess alcohol consumption and health outcomes: A 6-year follow-up of men over age 50 from the Health and Retirement Study. Addiction. 2002;97(3):301-310. DOI: /101046/ j1360-0443200200067x.

37. Lopes MA, Furtado EF,Ferrioli E, et al. Prevalence of alcohol-related problems in an elderly population and their association with cognitive impairment and dementia. Alcohol Clinical Experimental Research. 2010;34(4):726-733.DOI: /101111/j1530-0277200901142x.

38. Kuźma E, Llewellyn DJ, Langa KM, Wallace RB, Lang IA. History of alcohol use disorders and risk of severe cognitive impairment: A nineteen-year prospective cohort study. The American Journal of Geriatric Psychiatry. 2014; 22(10):1047-1054.DOI: /101016/ jjagp201406001.

39. Faul M, Xu L, Wald MM, Coronado VG. Traumatic brain injury in the United States: emergency department visits, hospitalizations and deaths. Atlanta, GA: Centers for Disease Control and Prevention. National Center for Injury Prevention and Control. 2010;2-70.

40. Daniel RW, Rowson S, Duma SM. Head impact exposure in youth football. Annals of Biomedical Engineering. 2012;40(4):976-987. DOI: /101007/s10439-012-0530-7.

41. Kerr ZY, Marshall SW, Guskiewicz KM. Reliability of concussion history in former professional players. Medicine and Science in Sports and Exercise. 2012;44(3):377-382. DOI: /101249/ MSS0b013e31823240f2.

42. Koerte IK, Ertl-Wagner B, Resier M, Zafonte R, Shenton ME. White matter integrity in the brains of professional soccer players without a symptomatic concussion. The Journal of the American Medical Association. 2012; 308(18):1859-1861. DOI: /101001/ jama201213735.

43. Johnson VE, Steward W, Smith DH. Widespread $\tau$ and amyloid- $\beta$ pathology many years after a single traumatic brain injury in humans. Brain Pathology. 2012;22(2):142-149. DOI: /101111/j17503639201100513x.

44. Dams-O'Connor K, Gibbons LE, Bowen JD, McCurry SM, Larson EB, Crane PK. Risk for late-life re-injury, dementia and death among individuals with traumatic brain injury: A population-based study. Neurosurgery and Psychiatry. 2013;84(2):177-182. DOI: /101136/ jnnp-2012-303938.

45. Moretti L, Crisofori I, Weaver SM, Chau A, Portelli JN, Grafman J. Cognitive decline in older adults with a history of traumatic brain injury. Lancet Neurology. 2012;11(12):1103-1112. DOI: /101016/ S1474-4422(12)70226-0.

46. Wang H, Lin SH, Sung P, Wu M, Hung K, Wang, et al. Population based study on patients with traumatic brain injury suggests increased risk of dementia. Journal of Neurology, Neurosurgery and Psychiatry. 2012;83(11): 1080-1085. DOI: /101136/jnnp-2012-302633.

47. Anstey KJ, Mack HA, \& Cherbuin N. Alcohol consumption as a risk factor for dementia and cognitive decline: meta-analysis of prospective studies. American Journal of Geriatric Psychiatry. 2009;17(7):542555. DOI: /101097/JGP0b013e3181a2fd07.

48. Peters R, Peters J, Warner J, etal. Alcohol dementia and cognitive decline in the elderly: a systematic review. Age Ageing. 2008;37(5):505-512. DOI: /101093/ageing/afn095.

49. Cataldo JK, Prochaska JJ, Glantz SA. Cigarette smoking is a risk factor for Alzheimer's Disease: an analysis controlling for tobacco industry affiliation. Journal of Alzheimer's Disease. 2010;19(2):465-480. doi: 10.3233/JAD-2010-1240.

50.Barnes DE, Yaffe K. The projected effect of risk factor reduction on Alzheimer's disease prevalence. The Lancet Neurology. 2011;10(9):819-828. DOI: /101016/S1474-4422(11)70072-2.

51. Chen R. Association of environmental tobacco smoke with dementia and Alzheimer's disease among never smokers. Alzheimer's and Dementia. 2012;8(6): 590-595. DOI: /101016/jjalz201109231.

52. Rusanen M, Kivipelto M, Quesenberry CP, Zhou J, Whitmer RA. Heavy smoking in midlife and long-term risk of Alzheimer disease and vascular dementia. Archives of Internal Medicine. 2011;171(4):333339. DOI: /101001/archinternmed2010393.

53. Qiu C. Lifestyle Factors in the Prevention of Dementia: A Life Course Perspective. In: Health and Cognition in Old Age Springer International Publishing. 2014;161-175. DOI: /101007/978-3-319-06650-9_11.

54. Pinkston JB, Alekseeva N, González Toledo E. Stroke and dementia. Neurological Research. 2009;31(8):824-831. DOI: /101179/016164 109X12445505689643.

55. Merino JG, Hachinski V. Stroke-related dementia. Current Atherosclerosis Reports. 2002;4(4):285-290. DOI: /101007/s11883002-0007-5.

56. Ivan CS, Seshadri S, Beiser A, Au R, Kase CS, Kelly-Hayes M, et al. Dementia after stroke the Framingham study. Stroke. 2004;35(6):1264-1268.DOI: /101161/01STR00001278109261678.

57. Bondy SC. Prolonged exposure to low levels of aluminum leads to changes associated with brain aging and neurodegeneration. Toxicology. 2014;315:1-7. doi: 10.1016/j.tox.2013.10.008.

58. Walton JR. Chronic Aluminum Intake Causes Alzheimer's Disease: Applying Sir Austin Bradford Hill's Causality Criteria. Journal of Alzheimer's Disease. 2014;40(4), 765-838. doi: 10.3233/JAD-132204.

59. Alfrey A.C, Mishell J.M, Burks J, Contiguglia S.R, Rudolph H, Lewin E, et al. Syndrome of dyspraxia and multifocal seizures associated with chronic hemodialysis. American Society of Artificial Internal Organs Journal. 1972;18: 257-261.

60. Algahtani HAAA,Al-Rabia MW. Dialysis Dementia: A Review Saudi Journal of Internal Medicine. 2014;4(1):29-35.

61. Bruce ME, Will RG, Ironside JW, McConnell I, Drummond D, Suttie A, et al. Transmissions to mice indicate that 'new variant' CJD is caused by the BSE agent. Nature. 1997;389(6650):498-501. DOI: /101038/39057.

62. Hill AF, Butterworth RJ, Joiner S, Jackson G,Rossor MN, Thomas DJ, et al. Investigation of variant Creutzfeldt-Jakob disease and other human prion diseases with tonsil biopsy samples. The Lancet. 1999;353(9148):183-189.

63. Danese A, McEwen BS. Adverse childhood experiences, allostasis, allostatic load, and age-related disease. Physiology \& Behavior. 2012;106(1): 29-39. doi: 10.1016/j.physbeh.2011.08.019. 
64. Lynch JW, Kaplan GA, Shema SJ. Cumulative impact of sustained economic hardship on physical, cognitive, psychological, and social functioning. N Engl J Med. 1997;337(26):1889-1895.

65. Moceri VM, Kukull WA, Emanuel I, et al. Early-life risk factors and the development of Alzheimer's disease. Neurology. 2000;54(2):415-420.

66. Ritchie K, Jaussent I, Stewart R, Dupuy AM, Courtet P, Malafosse A, et al. Adverse childhood environment and late-life cognitive functioning. International journal of geriatric psychiatry. 2011;26(5):503510. doi: 10.1002/gps.2553.

67. Maillard P, Fletcher E, Harvey D, Carmichael O, Reed B, Mungas D, et al. White matter hyperintensity penumbra. Stroke. 2011;42(7):19171922.DOI: /101161/STROKEAHA110609768.

68. Perusini G. Histology and Clinical Findings of Some Psychiatric Disease of older People, in Bick, K L, and Amaducci, L (Eds). The Early Story of Alzheimer's Disease: Translation of the Historical Papers by Alois Alzheimer, Oskar Fischer, Francesco Bonfiglio, Emil Kraepelin, Gaetano Perusini. Liviana Press. 1910.

69. Iqbal K, Lium F, Gong CX. Alzheimer disease therapeutics: Focus on the disease and not just plaques and tangles. Biochemical Pharmacology. 2014;88(4):631-639.DOI: /101016/jbcp201401002.

70. Alzheimer A, Förstl H, Levy R. On certain peculiar diseases of old age. History Psychiatry. 1991;2:71-101.

71. Fox NC, Freeborough PA, Rossor MN. Visualisation and quantification of rates of atrophy in Alzheimer's disease. The Lancet. 1996;348(9020):94-7.

72. Andrade-Moraes CH, Oliveira-Pinto AV, Castro-Fonseca E, da Silva CG Guimarães DM, Szczupak D,et al. Cell number changes in Alzheimer's disease relate to dementia, not to plaques and tangles. Brain. 2013;136(12), 3738-3752. DOI: /101093/brain/awt273.

73. Berlucchi G, Buchtel HA. Neuronal plasticity: historical roots and evolution of meaning. Experimental Brain Research. 2009;192(3):307319. DOI: /101007/s00221-008-1611-6.

74. Berlucchi G. History of Neuroscience:Ernesto Lugaro, IBRO. History of Neuroscience. 2002;Accessed. 2014; http://wwwibroinfo/Pub/PubM ainDisplayasp?LCDocsID=3477.

75. De Magalhaes JP, Sandberg A. Cognitive aging as an extension on brain development: a model linking learning, brain plasticity, and neurodegeneration. Mechanisms of Ageing and Development. 2004; 126(10):1026-1033. DOI: /101016/jmad200504004.

76. Leuner B, Gould E. Structural plasticity and hippocampal function. Annual Review of Psychology. 2010;61:111-140. DOI: /101146/ annurevpsych093008100359.

77. Ballesteros S, Nilsson L, \& Lemaire P. Ageing, cognition, and neuroscience: anintroduction.EuropeanJournalofCognitivePsychology. 2009;21(2-3),161-175. DOI:/101080/09541440802598339.

78. Shu-Chen L,Schmiedek F,Huxhold O,Rocke C, Smith J,Lindenberger U. Working memory plasticity in old age: Practice, gain, transfer, and maintenance. Psychology and Aging. 2008;23(4):731-742. DOI: /101037/a0014343

79. Snowdon DA, Greiner LH, Mortimer JA, Riley KP, Greiner PA, Markesbery WR. Brain infarction and the clinical expression of Alzheimer disease: the Nun Study. Journal of the American medical Association. 1997;277(10): 813-817. DOI: /101001/ jama199703540340047031.

80. Ott A, Breteler M, Van Harskamp F, Claus JJ, Van Der Cammen TJ Grobbee DE, et al. Prevalence of Alzheimer's disease and vascular dementia: association with education. The Rotterdam study. British Medical Journal. 1995; 310(6985):970-973. DOI: /101136/ bmj3106985970.

81. Mourany L,Pillai J. Education Effects On Rate Of Cognitive Decline Compared In Autopsy Confirmed Alzheimer's, Lewy Body And Vascular Dementia. Neurology. 2014;82(10 Supplement):5-239.

82. Cobb JL, Wolf PA, Au R, White R, D'agostino RB. The effect of education on the incidence of dementia and Alzheimer's disease in the Framingham Study. Neurology. 1995;45(9):1707-1712. DOI: /101212/WNL4591707.

83. De Oliveira TCG, Soares FC, De Macedo LEDD, Diniz DLWP, BentoTorres NVO, et al. Beneficial effects of multisensory and cognitive stimulation on age-related cognitive decline in long-term-care institutions. Clinical Interventions in Aging. 2014;9:309-321.

84. Karkou V, Meekums B. Dance movement therapy for dementia.The Cochrane Library. 2014.

85. Verghese J, LeValley A, Derby C, et al. Leisure activities and the risk of amnestic mild cognitive impairment in the elderly. Neurology. 2006;66(6):821-827. DOI: /101212/01wnl00002025206898748.

86. Wan CY, Schlaug G. Music making as a tool for promoting brain plasticity across the life span. The Neuroscientist. 2010;16(5):566577. DOI: /101177/1073858410377805.

87. Schmithorst VJ, Wilke M. Differences in white matter architecture between musicians and non-musicians: a diffusion tensor imaging study. Neuroscience. 2002;321(1-2):57-60. DOI: /101016/S03043940(02)00054-X.

88. Ball M. Limbic predilection in Alzheimer's dementia: is reactivated herpes virus involved?. Canadian Journal of Neurological Science. 1992;9(3):303-306.

89. Lampit A, Hallock H, Moss RK,wok S, Rosser M, Lukjanenko M,et al. The timecourse of global cognitive gains from supervised computerassisted cognitive training: a randomised, active-controlled trial in elderly with multiple dementia risk factors. Journal of the Prevention of Alzheimer's Disease. 2014;1:33-39.

90. Ball K, Berch DB, Helmers KF, Jobe JB, Willis SL. Advanced cognitive training for independent and vital elderly study group. The Journal of the American Medical Association. 2002;288(18):2271-2281. DOI: /101001/jama288182271.

91. Willis SL, Tennstedt SL, Marsiske M, Ball K, Elias J, Wright E, et al. Long-term effects of cognitive training on everyday functional outcomes in older adults. Journal of the American Medical Association. 2006;296(23):2805-2814. DOI: /101001/jama296232805.

92. Wolinsky FD, Unverzagt FW, Smith DM, Jones R, Stoddard A, Tennstedt SL. The ACTIVE cognitive training trial and health-related quality of life: protection that lasts for 5 years. The Journals of Gerontology Series A, Biological Sciences and Medical Sciences. 2006;61A(12):13241329. DOI: /101093/gerona/61121324.

93. Rebok GW, Ball K, Guey LT, Jones RN, Kim HY, King JW, et al. TenYear Effects of the Advanced Cognitive Training for Independent and Vital Elderly Cognitive Training Trial on Cognition and Everyday Functioning in Older Adults. Journal of the American Geriatrics Society. 2014;62(1):16-24. DOI: /101111/jgs12607.

94.Erickson KI, Voss MW, Prakash RS, Basak C, Szabo A, Chaddock L,et al. Exercise training increases size of hippocampus and improves memory. Proceedings of the National Academy of Sciences. 2011;108(7):3017-3022. DOI: /101073/pnas1015950108.

95. Gage FH. Brain, repair yourself. Scientific American. 2003;289(3):46- 


\section{DOI: /101038/scientificamerican0903-46.}

96. Wan CY, Schlaug G. Music making as a tool for promoting brain plasticity across the life span. The Neuroscientist. 2010;16(5):566577. DOI: /101177/1073858410377805.

97. Wolinsky FD, Vander Weg MW, Martin R, Unverzagt FW, Ball,et al The effect of speed-of-processing on depressive symptoms in ACTIVE. The Journals of Gerontology Series A, Biological Sciences and Medical Sciences. 2009; 64(4):468-472. DOI: /101093/gerona/gln044.

98. Wolinsky FD, Unverzagt FW, Smith DM, Jones R, Stoddard A, Tennstedt SL. The ACTIVE cognitive training trial and health-related quality of life: Protection that lasts for 5 years. The Journals of Gerontology Series A: Biological Sciences and Medical Sciences. 2006;61(12):13249.

99. Olichney JM, Hansen LA, Hoffstetter FR, Grundman M, Katzman R, Tha LJ. The apolipoprotein epsilon 4 allele is associated with increased neuritic plaques and CAA in Alzheimer's disease and Lewy body variant. Neurology. 1996;47(1):190-196. DOI: /101212/WNL471190.

100. Premkumar DRD, Cohen DL, Hedera P, Friedland RP, Kalaria RN. Apolipoprotein E $\varepsilon 4$ alleles in CAA and cerebrovascular pathology in Alzheimer's disease. American Journal of Pathology.1996;148:2083-2095.

101. De la Torre JC. Is Alzheimer's disease a neurodegenerative or a vascular disorder? Data, dogma, and. The Lancet Neurol. 2004;3(3):184-190. DOI: /101016/S1474-4422(04)00683-0.

102. Greene NH, Lee LA. Modern and Evolving Understanding of Cerebral Perfusion and Autoregulation. Advances in Anesthesia. 2012;30:97129. DOI: /101016/jaan201208003.

103. Gomolin IH, Aung MM, Wolf-Klein G, Auerbach C. Older is colder: temperature range and variation in older people. Journal of the American Geriatrics Society. 2005;53(12):2170-2172. DOI: /101111/j1532-5415200500500x.

104. Sund-Levander M, Forsberg C, Wahren LK. Normal oral, rectal, tympanic and axillary body temperature in adult men and women: a systematic literature review. Scandinavian Journal of Caring Sciences. 2002;16(2):122-128. DOI: /101046/j1471-6712200200069x.

105. Roth GS, Lane MA, Ingram DK, Mattison JA, Elahi D, Tobin JD, Muller D, et al. Biomarkers of caloric restriction may predict longevity in humans. Science. 2002;297(5582):811. DOI: /101126/ science1071851.

106. Rogers RL, Meyer JS, Mortel KF. After reaching retirement age physical activity sustains cerebral perfusion and cognition. Journal of the American Geriatric Society. 1990;38(2):123-128.
107. Gorelick PB, Scuteri A, Black SE, DeCarli C, Greenberg SM, Iadecola C, et al. Vascular contributions to cognitive impairment and dementia a statement for healthcare professionals from the American Heart Association/American Stroke Association. Stroke. 2011;42(9):26722713. DOI: /101161/STR0b013e3182299496.

108. de Bruijn RF, Schrijvers EM, de Groot KA, Witteman JC, Hofman A, Franco $\mathrm{OH}$, et al. The association between physical activity and dementia in an elderly population: the Rotterdam Study.European Journal of Epidemiology. 2013;28(3):277-283. DOI: /101007/ s10654-013-9773-3.

109. Pedersen BK. The diseasome of physical inactivity-and the role of myokines in muscle-fat cross talk. The Journal of Physiology. 2009;587(23):5559-5568. DOI: /101113/jphysiol2009179515.

110. Morgan GS, Gallacher J, Bayer A, Fish M, Ebrahim S, Ben-Shlomo Y. Physical activity in middle-age and dementia in later life: findings from a prospective cohort of men in Caerphilly, South Wales and a meta-analysis. Journal of Alzheimer's Disease. 2012;31(3):569-580. doi: 10.3233/JAD-2012-112171.

111. de la Torre JC, Aliev G. Inhibition of vascular nitric oxide after rat chronic brain hypoperfusion: spatial memory and immunocytochemical changes. Journal of Cerebral Blood Flow \& Metabolism. 2005;25(6):663-672.

112. Bittner EA, Yue Y, Xie Z. Brief review: anesthetic neurotoxicity in the elderly, cognitive dysfunction and Alzheimer's disease. Canadian Journal of Anesthesia. 2011;58(2):216-223. DOI: /101007/s12630010-9418-x.

113. Casati A, Fanelli G, Pietropaoli P, Proietti R, Tufano R, Montanini $\mathrm{S}$, et al. Monitoring cerebral oxygen saturation in elderly patients undergoing general abdominal surgery: a prospective cohort study. European Journal of Anaesthesiology. 2007;24(01):59-65. DOI: /101017/S0265021506001025 DOI:/101097/00003643200701000-00010.

114. Zheng W, ZhuGe Q, Zhong M, Chen G, Shao B, Jin K. Neurogenesis in adult human brain after traumatic brain injury. Journal of Neurotrauma. 2013;30(22):1872-1880. DOI: /101089/ neu20101579

115. Phillips H. Outer limits of the brain. New Scientist. 2008;28-33. DOI: /101016/S0262-4079(08)62502-6.

116. Evert J, Lawler E, Bogan H, Perls T. Morbidity profiles of centenarians: survivors, delayers, and escapers. The Journals of Gerontology Series A: Biological Sciences and Medical Sciences. 2003;58(3):232237. DOI: /101093/gerona/583M232. 